\title{
Cu-Mediated trifluoromethylation of benzyl, allyl and propargyl methanesulfonates with $\mathrm{TMSCF}_{3}$
}

\author{
Xueliang Jiang ${ }^{1}$ and Feng-Ling Qing ${ }^{* 1,2}$
}

\author{
Full Research Paper \\ Address: \\ ${ }^{1}$ Key Laboratory of Organofluorine Chemistry, Shanghai Institute of \\ Organic Chemistry, Chinese Academy of Sciences, 345 Lingling Lu, \\ Shanghai 200032, China and ${ }^{2}$ College of Chemistry, Chemical \\ Engineering and Biotechnology, Donghua University, 2999 North \\ Renmin Lu, Shanghai 201620, China \\ Email: \\ Feng-Ling Qing* - flq@mail.sioc.ac.cn \\ * Corresponding author \\ Keywords: \\ copper; methanesulfonates; organo-fluorine; trifluoromethylation
}

Beilstein J. Org. Chem. 2013, 9, 2862-2865.

doi:10.3762/bjoc. 9.322

Received: 18 September 2013

Accepted: 25 October 2013

Published: 12 December 2013

This article is part of the Thematic Series "Organo-fluorine chemistry III".

Guest Editor: D. O'Hagan

(C) 2013 Jiang and Qing; licensee Beilstein-Institut.

License and terms: see end of document.

\begin{abstract}
A Cu-mediated trifluoromethylation of benzyl, allyl and propargyl methanesulfonates with $\mathrm{TMSCF}_{3}$ was developed for the first time. This method offers a convenient and economical approach to various trifluoroethyl-containing compounds.
\end{abstract}

\section{Introduction}

Fluorinated organic molecules are extremely important in agrochemicals, pharmaceuticals and materials [1-6]. In recent years, (trifluoroethyl)arenes have drawn increasing attention in medicinal chemistry and related fields [7-9]. Different methods have been developed for the synthesis of (trifluoroethyl)arenes, such as $\mathrm{Cl}-\mathrm{F}$ exchange of the trichloroethyl derivatives [10], reduction of the (trifluoroethyl)aryl derivatives [11] and addition of 2,2-difluorostyrene derivatives [12]. Compared to these methods, the direct transition metal-mediated trifluoroethylation of arylboronic acids [13,14] (Scheme 1a) and trifluoromethylation of benzyl halides [15-21] (Scheme 1b) are more convenient. Especially trifluoromethylations of benzyl bromides with a $\left[\mathrm{CuCF}_{3}\right]$ species, which are generated from different precursors, are generally employed to afford various (trifluoroethyl)arenes. Although these methods are proven efficient, it is still highly desirable to develop new protocols from economic consideration. In continuation of our research on transition metal-mediated trifluoromethylation [22-27], we report here the first example of $\mathrm{Cu}$-mediated trifluoromethylation of benzyl methanesulfonates (Scheme 1c).

\section{Results and Discussion}

We initiated our investigation by reacting benzyl methanesulfonate 1a with $\mathrm{TMSCF}_{3}$ (2.0 equiv) in the presence of $\mathrm{KF}$ (2.0 equiv) and $\mathrm{CuI}\left(0.2\right.$ equiv) in $\mathrm{DMF}(2.0 \mathrm{~mL})$ at $60{ }^{\circ} \mathrm{C}$ under Ar atmosphere. However, only $17 \%$ yield of the desired product 2 a was observed in this case (Table 1, entry 1). The yield was improved to $31 \%$ when the reaction was carried out in 


\section{Previous work}

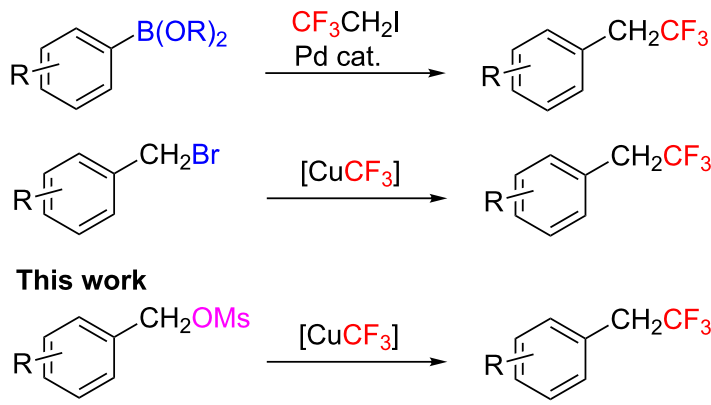

Scheme 1: Transition metal-mediated methods for the preparation of (trifluoroethyl)arenes.

the presence of 1,10-phenanthroline (phen) (Table 1, entry 2). Increasing the substrate concentration (from $0.1 \mathrm{M}$ to $0.4 \mathrm{M}$ ) could further improve the product yield to $49 \%$ (Table 1 , entries 3 and 4). Other copper salts such as $\mathrm{CuBr}, \mathrm{CuCl}, \mathrm{CuTc}$ and $\mathrm{CuOAc}$, were next screened, but none of them was better than $\mathrm{CuI}$ (Table 1, entries 5-8). Interestingly, when the benzyl methanesulfonate reacted with $\left[\mathrm{CuCF}_{3}\right]$ generated in situ from $\mathrm{TMSCF}_{3}$ and a stoichiometric amount of $\mathrm{CuI}$ ( 1.1 equiv) without phen, the desired product $\mathbf{2 a}$ was formed in $68 \%$ yield (Table 1, entry 9). Decreasing or increasing the amount of CuI resulted in a lower yield (Table 1, entries 10 and 11). The solvent was next screened and, to our delight, the highest yield of the product was achieved when using DMF/HMPA (1:1) as the mixed solvent (Table 1, entry 14).

With the optimal conditions in hand, we next examined the substrate scope of the $\mathrm{Cu}$-mediated trifluoromethylation of benzyl methanesulfonates with $\mathrm{TMSCF}_{3}$ (Scheme 2). This method tolerates various functional groups. A wide range of benzyl methanesulfonates bearing electron-withdrawing groups, such as nitro (1f), cyano (1g), trifluoromethyl (1h) and ester (1i), as well as electron-donating groups such as phenyl (1b), smoothly underwent the transformation, affording the desired products in moderate to good yield. Importantly, both chloro (1d) and bromo (1e) substituents are also compatible with this method. It is particularly noteworthy that the reaction can be scaled up efficiently. 2a and 2c were successfully prepared on $10 \mathrm{mmol}$ scale, indicating the good reliability of the process.

The present reaction could also be expanded to the trifluoromethylation of allylic methanesulfonates (Scheme 3). Treatment of the substrate $\mathbf{1 k}$ under the standard reaction conditions afforded the linear trifluoromethylated product $\mathbf{2 k}$ in $78 \%$ yield with a trace amount of $Z$ isomer. Interesting, the reactions with the allylic methanesulfonates $\mathbf{1 1}$ and $\mathbf{1} \mathbf{m}$ gave the same regioselectivity and stereoselectivity with good yields. These observations indicate that a $\pi$-allyl $/ \mathrm{Cu}^{\text {ш }}$ complex might be involved in the $\mathrm{C}_{\mathrm{sp} 3}-\mathrm{CF}_{3}$ bond formation, but the detailed mechanism remains to be elucidated.

Table 1: Optimization of the reaction conditions. ${ }^{a}$

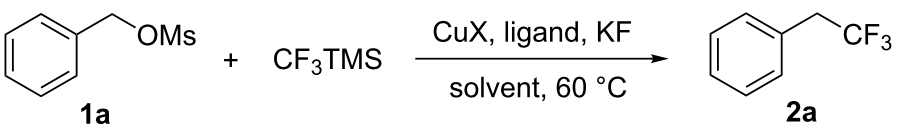

\begin{tabular}{|c|c|c|c|c|}
\hline entry & CuX (equiv) & ligand & solvent & yield of $2 \mathrm{a}(\%)^{\mathrm{b}}$ \\
\hline $1^{\mathrm{C}}$ & Cul (0.2) & - & DMF & 17 \\
\hline $2^{c}$ & Cul (0.2) & phen & DMF & 31 \\
\hline $3^{d}$ & Cul (0.2) & phen & DMF & 32 \\
\hline 4 & Cul (0.2) & phen & DMF & 49 \\
\hline 5 & $\mathrm{CuBr}(0.2)$ & phen & DMF & 40 \\
\hline 6 & $\mathrm{CuCl}(0.2)$ & phen & DMF & trace \\
\hline $7^{e}$ & CuTc (0.2) & phen & DMF & trace \\
\hline 8 & CuOAc & phen & DMF & trace \\
\hline 9 & Cul (1.1) & - & DMF & 68 \\
\hline 10 & Cul (1.5) & - & DMF & 66 \\
\hline 11 & Cul (1.0) & - & DMF & 62 \\
\hline 12 & Cul (1.1) & - & DMSO & 38 \\
\hline 13 & Cul (1.1) & - & HMPA & 9 \\
\hline 14 & Cul (1.1) & - & DMF/HMPA (1:1) & 76 \\
\hline
\end{tabular}

aReaction conditions: $1 \mathrm{a}(0.2 \mathrm{mmol})$, ligand $(0.2 \mathrm{mmol}), \mathrm{TMSCF}_{3}(0.4 \mathrm{mmol}), \mathrm{KF}(0.4 \mathrm{mmol}), \mathrm{DMF}(0.5 \mathrm{~mL}), 60^{\circ} \mathrm{C}$, under Ar atmosphere. ${ }^{\text {bYield was }}$ determined by ${ }^{19} \mathrm{~F}$ NMR using benzotrifluoride as an internal standard. ${ }^{\mathrm{c}} 2.0 \mathrm{~mL}$ of DMF. ${ }^{\mathrm{d}} 1.0 \mathrm{~mL}$ of DMF. ${ }^{\mathrm{e}} \mathrm{CuTc}$ is copper(I) thiophene-2-carboxylate. 


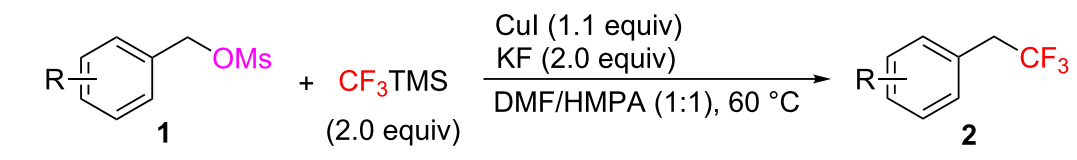<smiles>FC(F)(F)Cc1ccccc1</smiles>

$2 a, 76 \%$ a<smiles>FC(F)(F)Cc1ccc(-c2ccccc2)cc1</smiles>

2b, $79 \%$<smiles>Fc1ccc(CC(F)(F)F)cc1</smiles>

2c, $75 \%$ a<smiles>FC(F)(F)Cc1cc(Cl)cc(Cl)c1</smiles>

2d, $72 \%$<smiles>FC(F)(F)Cc1ccc(Br)cc1</smiles>

$2 e, 78 \%$<smiles>O=[N+]([O-])c1ccc(CC(F)(F)F)cc1</smiles>

2f $40 \%$<smiles>N#Cc1cccc(CC(F)(F)F)c1</smiles>

2 g, $81 \%$<smiles>FC(F)(F)Cc1ccc(C(F)(F)F)cc1</smiles>

2h, $80 \%$<smiles>CC(=O)c1ccc(CC(F)(F)F)cc1</smiles>

2i, $68 \%$<smiles>FC(F)(F)Cc1ccc2ccccc2c1</smiles>

2j, $78 \%$

Scheme 2: Cu-mediated trifluoromethylation of benzyl methanesulfonates. Reaction conditions: 1 (2.0 mmol), Cul (2.2 mmol), TMSCF 3 (4.0 mmol), $\mathrm{KF}(4.0 \mathrm{mmol}), \mathrm{DMF} / \mathrm{HMPA}(1: 1,5.0 \mathrm{~mL}), 60^{\circ} \mathrm{C}$, under Ar atmosphere; Isolated yield. alsolated yield after distillation on $10.0 \mathrm{mmol}$ scale.

(a)

$$
\begin{aligned}
& \text { YMs CF } \mathrm{CF}_{3} \text { TMS (2.0 equiv) } \\
& \text { 1k or } \quad \stackrel{\mathrm{KF}(2.0 \text { equiv })}{\mathrm{Kul}(1.1 \text { equiv) }}
\end{aligned}
$$

Scheme 3: Cu-Mediated trifluoromethylation of allyl methanesulfonates.

We were next interested in the trifluoromethylation of propargyl methanesulfonate derivates. Both aliphatic and aryl-substituted linear propargyl methanesulfonates under standard reaction conditions afforded the corresponding trifluoromethylated propargylic products in moderate yields (Scheme 4a). However, the reaction of the branched substrates under identical conditions gave the trifluoromethylated allenylic products in good to excellent yields, without any trifluoromethylated propargylic products (Scheme 4b). Thus, this reaction provides an efficient protocol for the synthesis of allenylic- $\mathrm{CF}_{3}$ derivatives, which are useful building blocks for pharmaceuticals [28,29].

\section{Conclusion}

In summary, we have developed an efficient copper-mediated trifluoromethylation of benzyl methanesulfonates at the benzylic position under mild conditions. The reaction can be

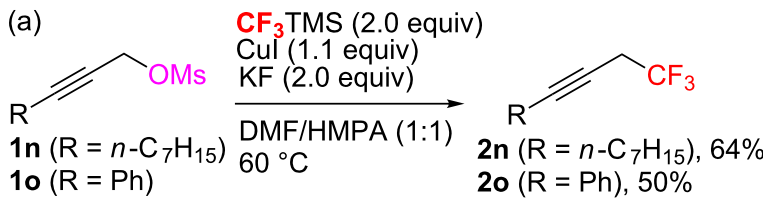
(b)
$1 \mathrm{p}(\mathrm{R}=\mathrm{Me})$
2p $(\mathrm{R}=\mathrm{Me}), 89 \%$
$1 \mathrm{q}(\mathrm{R}=n-\mathrm{Bu})$
$2 \mathrm{q}(\mathrm{R}=n-\mathrm{Bu}), 93 \%$
$\operatorname{1r}(\mathrm{R}=\mathrm{TMS})$
$2 r(R=T M S), 70 \%$

Scheme 4: Cu-Mediated trifluoromethylation of propargyl methanesulfonates.

easily scaled up and allows for the efficient synthesis of a series of (trifluoroethyl)arenes with excellent functional group compatibility. Furthermore, the method could also be extended to the trifluoromethylation of allyl and progargyl methanesulfonates, affording the corresponding allylic-, progargylic- and allenylic- $\mathrm{CF}_{3}$ derivatives.

\section{Experimental}

General procedure for the $\mathrm{Cu}$-mediated trifluoromethylation of benzyl methanesulfonates: $\mathrm{CuI}(2.2 \mathrm{mmol})$ and $\mathrm{KF}$ $(4.0 \mathrm{mmol})$ were added into a Schlenk tube equipped with a magnetic stirring bar under Ar atmosphere. DMF (5.0 mL) and $\mathrm{Me}_{3} \mathrm{SiCF}_{3}$ (2.0 equiv) were added. After stirring for 20 minutes, the mixture was heated to $60{ }^{\circ} \mathrm{C}$ and then benzyl methanesulfonate $(2.0 \mathrm{mmol})$ was added under $\mathrm{N}_{2}$ atmosphere. The reaction mixture was kept at $60{ }^{\circ} \mathrm{C}$ for 4 hours and then cooled to 
room temperature. The resulting mixture was diluted with diethyl ether, washed with water and brine, dried over sodium sulfate, and concentrated. The crude products were purified by column chromatography on silica gel to give the products.

\section{Supporting Information}

\section{Supporting Information File 1}

Experimental details, characterization data of all products and copies of NMR spectra.

[http://www.beilstein-journals.org/bjoc/content/ supplementary/1860-5397-9-322-S1.pdf]

\section{Acknowledgements}

We gratefully acknowledge National Natural Science Foundation of China $(21072028,21272036)$ and National Basic Research Program of China (2012CB21600).

\section{References}

1. Kirsch, P. Modern Fluoroorganic Chemistry; Wiley-VCH: Weinheim, 2004. doi:10.1002/352760393X

2. Uneyama, K. Organofluorine Chemistry; Blackwell: Oxford, U.K., 2006. doi:10.1002/9780470988589

3. Ojima, I. Fluorine in Medicinal Chemistry and Chemical Biology; Wiley-Blackwell: Chichester, U.K., 2009.

4. Müller, K.; Faeh, C.; Diederich, F. Science 2007, 317, 1881-1886. doi:10.1126/science.1131943

5. Kirk, K. L. Org. Process Res. Dev. 2008, 12, 305-321. doi:10.1021/op700134j

6. O'Hagan, D. Chem. Soc. Rev. 2008, 37, 308-319. doi:10.1039/b711844a

7. Shi, G. Q.; Dropinski, J. F.; Zhang, Y.; Santini, C.; Sahoo, S. P.; Berger, J. P.; MacNaul, K. L.; Zhou, G.; Agrawal, A.; Alvaro, R.; Cai, T.-Q.; Hernandez, M.; Wright, S. D.; Moller, D. E.; Heck, J. V.; Meinke, P. T. J. Med. Chem. 2005, 48, 5589-5599. doi:10.1021/jm050373g

8. Parrish, C. A.; Adams, N. D.; Auger, K. R.; Burgess, J. L.; Carson, J. D.; Chaudhari, A. M.; Copeland, R. A.; Diamond, M. A.; Donatelli, C. A.; Duffy, K. J.; Faucette, L. F.; Finer, J. T.; Huffman, W. F.; Hugger, E. D.; Jackson, J. R.; Knight, S. D.; Luo, L.; Moore, M. L.; Newlander, K. A.; Ridgers, L. H.; Sakowicz, R.; Shaw, A. N.; Sung, C.-M. M.; Sutton, D.; Wood, K. W.; Zhang, S.-Y.; Zimmerman, M. N.; Dhanak, D. J. Med. Chem. 2007, 50, 4939-4952. doi:10.1021/jm070435y

9. Macsari, I.; Besidski, Y.; Csjernyik, G.; Nilsson, L. I.; Sandberg, L.; Yngve, U.; Åhlin, K.; Bueters, T.; Eriksson, A. B.; Lund, P.-E.; Venyike, E.; Oerther, S.; Hygge Blakeman, K.; Luo, L.; Arvidsson, P. I. J. Med. Chem. 2012, 55, 6866-6880. doi:10.1021/jm300623u

10. Ando, A.; Miki, T.; Kumadaki, I. J. Org. Chem. 1988, 53, 3637-3639. doi:10.1021/jo00250a049

11. Uneyama, K.; Momota, M.; Hayashida, K.; Itoh, T. J. Org. Chem. 1990, 55, 5364-5368. doi:10.1021/jo00306a013

12. Nguyen, B. V.; Burton, D. J. J. Org. Chem. 1997, 62, 7758-7764. doi:10.1021/jo971019w
13. Zhao, Y.; Hu, J. Angew. Chem., Int. Ed. 2012, 51, 1033-1036. doi:10.1002/anie.201106742

14. Liang, A.; Li, X.; Liu, D.; Li, J.; Zou, D.; Wu, Y.; Wu, Y. Chem. Commun. 2012, 48, 8273-8275. doi:10.1039/c2cc31651j

15. Kobayashi, Y.; Yamamoto, K.; Kumadaki, I. Tetrahedron Lett. 1979, 20 , 4071-4072. doi:10.1016/S0040-4039(01)86506-0

16. Urata, H.; Fuchikami, T. Tetrahedron Lett. 1991, 32, 91-94. doi:10.1016/S0040-4039(00)71226-3

17. Chen, Q.-Y.; Duan, J.-X. J. Chem. Soc., Chem. Commun. 1993, 1389-1391. doi:10.1039/C39930001389

18. Kim, J.; Shreeve, J. M. Org. Biomol. Chem. 2004, 2, 2728-2734 doi:10.1039/b412480b

19. Dubinina, G. G.; Furutachi, H.; Vicic, D. A. J. Am. Chem. Soc. 2008, 130, 8600-8601. doi:10.1021/ja802946s

20. Dubinina, G. G.; Ogikubo, J.; Vicic, D. A. Organometallics 2008, 27, 6233-6235. doi:10.1021/om800794m

21. Kawai, H.; Furukawa, T.; Nomura, Y.; Tokunaga, E.; Shibata, N. Org. Lett. 2011, 13, 3596-3599. doi:10.1021/ol201205t

22. Chu, L.; Qing, F.-L. J. Am. Chem. Soc. 2010, 132, 7262-7263. doi:10.1021/ja102175w

23. Chu, L.; Qing, F.-L. Org. Lett. 2010, 12, 5060-5063. doi:10.1021/ol1023135

24. Chu, L.; Qing, F.-L. J. Am. Chem. Soc. 2012, 134, 1298-1304. doi:10.1021/ja209992w

25. Jiang, X.; Chu, L.; Qing, F.-L. J. Org. Chem. 2012, 77, 1251-1257. doi:10.1021/jo202566h

26. Chu, L.; Qing, F.-L. Org. Lett. 2012, 14, 2106-2109. doi:10.1021/ol300639a

27. Wu, X.; Chu, L.; Qing, F.-L. Angew. Chem., Int. Ed. 2013, 52, 2198-2202. doi:10.1002/anie.201208971

28. Zhao, T. S. N.; Szabó, K. J. Org. Lett. 2012, 14, 3966-3969. doi:10.1021/ol3017287

29. Miyake, Y.; Ota, S.; Shibata, M.; Nakajima, K.; Nishibayashi, Y. Chem. Commun. 2013, 49, 7809-7811. doi:10.1039/c3cc44434a

\section{License and Terms}

This is an Open Access article under the terms of the Creative Commons Attribution License (http://creativecommons.org/licenses/by/2.0), which permits unrestricted use, distribution, and reproduction in any medium, provided the original work is properly cited.

The license is subject to the Beilstein Journal of Organic Chemistry terms and conditions: (http://www.beilstein-journals.org/bjoc)

The definitive version of this article is the electronic one which can be found at: doi:10.3762/bjoc. 9.322 